\title{
Zhuang Chinese
}

National Cancer Institute

\section{Source}

National Cancer Institute. Zhuang Chinese. NCI Thesaurus. Code C158159.

A Chinese person from the Zhuang ethnic group. 